\title{
Exploration on the Mode of Innovation and Entrepreneurship Education in Commercial Universities
}

\author{
Yanan Wang \\ Xi’an Fanyi University, Xi’an, China
}

Keywords: Commerce; Innovation and entrepreneurship; Education model

\begin{abstract}
The essence of innovation and entrepreneurship education is a kind of practical education. The implementation of innovation and entrepreneurship education mode in Colleges and universities can enhance students' sense of innovation and innovation, improve their comprehensive quality and enhance their competitiveness in employment. Due to their professional characteristics and lack of mature experience and lack of guidance theory, business colleges and universities have big problems in innovation and entrepreneurship education in the current situation. Aiming at the problem of innovation and entrepreneurship education in business schools, this paper puts forward the "one center, four engine" education mode and analyzes it, and takes a business college as an example to make an empirical analysis.
\end{abstract}

\section{Introduction}

Twenty-first Century is an era of innovation, creation and entrepreneurship. National economic development and social progress depend more and more on the level of technological innovation and the cultivation of innovative talents. The 18th National Congress put forward that the reform of economic system and the development of economy should be driven by the strategy of innovation driven development, so that technological innovation can be upgraded to the strategic level of the overall development of the country. College students are one of the most innovative and entrepreneurial potential groups. The Ministry of education in Colleges and universities "on promoting innovation and entrepreneurship education and Entrepreneurship of university students work opinions" pointed out: "carrying out innovation and entrepreneurship education in Colleges and universities, actively encourage college students to start their own businesses, is the practice of Scientific Outlook on Development depth learning education system, major strategic initiatives to serve the innovative country construction; deepen the teaching reform of higher education. An important way to cultivate students' innovative spirit and practice ability; is the implementation of entrepreneurship to promote employment, an important measure to promote the full employment of College graduates".

\section{Analysis on the current situation of innovation and entrepreneurship education in Business Colleges}

\subsection{Students in general lack innovation and entrepreneurial consciousness.}

Chinese college innovation and entrepreneurship education in the initial stage, the state has promulgated a series of incentives, but the overall impact of traditional culture, college students' innovation consciousness is weak, from the employment tendency can be seen, keen to apply for civil service and stable work units, the employment of college students is generally the pursuit of stability, lack of the spirit of adventure however, entrepreneurial innovation itself has a greater risk, the probability of success is not high, the students lack of mobility. Especially in the business schools, the relative engineering colleges and universities pay more attention to the theory teaching, which leads to the lack of innovative and entrepreneurial consciousness of the students. 


\subsection{The model of innovation and entrepreneurship education is scarce.}

First of all, most universities in China to double the goal of education positioning is not clear, even the two separated. In a survey of innovation and entrepreneurship education courses in ten ordinary universities in China, it is found that most universities in China are learning from foreign universities, and lack of courses suitable for their own colleges or students' professional characteristics. Secondly, entrepreneurship education curriculum innovation in most commercial colleges by campus lectures or elective courses to carry out the form, not in accordance with the compulsory courses; again, for double major practice organized by the relevant business competition form, many of the same school, did not highlight their characteristics.

\subsection{Innovation and entrepreneurship education teachers are weak.}

Most of the teachers are trained in business colleges, from school to school, so basically no entrepreneurial experience, and lack of entrepreneurial theory of training system, the curriculum system of Professor process is to teach students the rich practical experience, it is difficult to drive innovation and entrepreneurial enthusiasm of students, limit the development of innovation and entrepreneurship education in Colleges and universities. Business universities sometimes invite well-known entrepreneurs or outstanding alumni to give lectures to students, but they may also have little effect on their lack of theoretical teaching experience. It can be seen that the innovative and entrepreneurial teachers of excellent majors are the important guarantee for the school to carry out innovative and entrepreneurial education.

\subsection{The university innovation and entrepreneurship education lacks the strong safeguard measure.}

The all-round development of innovation and entrepreneurship education is influenced by many factors, which requires coordination and cooperation in many aspects. However, the following aspects are slightly inadequate. First, government and university policy support for entrepreneurship education is not enough. It shows that there is not enough maneuverability of entrepreneurship policy for graduated students, insufficient publicity, and lack of policy measures for students to start their own business. Second, there is a shortage of start-up capital. A limited number of venture funds set up by institutions such as universities and governments will not solve the capital requirements for students to start their own businesses. Finally, the results are difficult to achieve. The development of the site, operation mode and management system of the pioneer park has restricted the successful transformation of students' entrepreneurial practice and project achievements.

\section{Business school innovation and entrepreneurship education model design}

In understanding the current business innovation entrepreneurship education in our country, built in the business college students as the center, including business schools, the local government, the relevant financial institutions, a startup hub platform, "one center, four engines of innovation" entrepreneurial education mode

\subsection{The supporting role of business colleges and universities on Students.}

Business colleges should support the students' innovative undertaking activities, cultivating innovative entrepreneurial culture atmosphere, integrate various resources, draw lessons from foreign advanced education mode at the same time, build education suitable for their own development of the whole team, continue to build, strengthen the students creative consciousness, To establish a double - division teaching staff combining the internal and external part-time work, give teacher talent security, on the one hand, can be sent the school teachers to enterprises, well-known colleges and universities to study, communication, on the other hand may also employ external innovation mentors of double gen guide for students. In a word, the school should create all the conditions to provide all-round support for student innovation and entrepreneurship. 


\subsection{The policy support of government institutions on students' innovation and Entrepreneurship.}

In the model of innovation and entrepreneurship education, the government should play its leading role, and constantly establish and improve college students' innovation and entrepreneurship policy system and the legal system, and establish the corresponding service system so that students can better accept innovative entrepreneurship education, to carry out the relevant practice. For example, in college students' innovation and entrepreneurship activities or practice, training fees can be reduced, procedures for related procedures streamlined and preferential policies tilted, and corresponding safeguards can be issued to provide graduates with platform for entrepreneurship.

\subsection{Financial institutions' financial support for students' innovation and Entrepreneurship.}

Current in "public entrepreneurship, peoples innovation", the new normal by financial institutions also need to intensify services in innovative undertaking, further deepen the financial support for entrepreneurial innovation service consciousness, active docking innovative start-ups, can establish entrepreneurial innovation project library, support on college students as the main body of the business group, boost the financial sector and real economy coexistence and co-prosperity. Increasing financial support for entrepreneurship and innovation; We will further innovate the product models of financial support for entrepreneurship and innovation, such as providing personal insurance services for innovative and entrepreneurial enterprises.

\subsection{The incubating effect of enterprise in the entrepreneurial park on students' innovation and Entrepreneurship Project.}

Startup hubs should constantly strengthen the industry guidance, policy integration, typical demonstration, public services, publicity, to boost students' innovative entrepreneurial platform construction, the construction of human resources platform, provide human and intellectual support for the innovative entrepreneurs; Building incubation platform to provide hardware foundation for innovative entrepreneurs; Build an e-commerce platform to broaden the development channels for innovative entrepreneurs. Enterprises in the park can strengthen cooperation with relevant institutions, schools can dig through the park also inside and outside all sorts of social resources, expanding business channels, lead the students out of the campus, joint enterprise, society to carry out targeted entrepreneurship education, effectiveness of innovation.

\section{The fuzzy hierarchical evaluation of the education model of innovation and entrepreneurship in business schools}

Business innovation entrepreneurship education schools, government, and the operation of social collaboration is systematic engineering, its evaluation has certain complexity, this paper using the fuzzy analytic hierarchy process (ahp), a business college in xi 'an as an example to evaluate its innovative entrepreneurial education mode. Its basic idea is: to determine the weights of evaluation factors, factors of evaluation level and on the basis of using the fuzzy set transform principle, the membership degree which is used to describe a factor, the factor of fuzzy boundaries, constructs the fuzzy matrix, through multiple layers of compound operations, finally decide the rank evaluation objects. The selection of the index system will follow scientific and reasonable principles and the establishment of expert opinions.

\subsection{The evaluation index}

\subsubsection{Government support.}

There are two secondary indicators of policy support and expenditure in the primary index supported by government agencies. Among them, the policy support indicators include government agencies' support for innovation and entrepreneurship, education's related policy issues and implementation, policy publicity and related services. The expenditure indicator refers to the proportion of expenditure of innovation and start-up expenses as the proportion of total education 
funds and the establishment of innovation and entrepreneurship base construction expenses.

\subsubsection{Business school support.}

The school support indicators include two secondary indicators of school environment and curriculum quality. The school environment index refers to the school hardware environment facilities, various safeguards measures, the campus innovation and entrepreneurship atmosphere. The specific includes: the construction quantity of the campus and the internal and external practice base, the number of entrepreneurship competition, the number of innovation and entrepreneurship association, the number of academic report exchanges and so on. The course quality index includes the number of courses of innovation and entrepreneurship, the proportion of innovation and entrepreneurship and part-time teachers, and the feedback of students on the innovation and entrepreneurship teaching.

\subsubsection{Support of entrepreneurship platform.}

The support indicators of entrepreneurial platform include two secondary indexes: entrepreneurship park and school enterprise cooperation. Among them, the index includes the environment of the hardware in the park, the number of entrepreneurship and training and the number of training. The school enterprise cooperation indicators include the number of bases for students to work in enterprises, and the incubation rate of students innovation and entrepreneurship in enterprises.

\subsubsection{Financial platform support.}

Financial platform support indicators include two secondary indicators of financial institutions and other intermediaries. The indicators of financial institutions include the preferential policies of Banks on innovation and entrepreneurship programs, and the number of support for projects. Other intermediary agency indicators include information services such as consultation and guidance provided by intermediary service agencies.

\subsubsection{Student quality.}

Students' quality indicators include students' personal background information and students' performance of two secondary indicators. Among them, the personal background information index includes the family background, experience, educational background and other factors influencing its entrepreneurship. Students' performance indicators include students' interest in innovation and entrepreneurship, such as the number of students participating in innovative entrepreneurship courses, the proportion of students involved, the attendance rate of relevant practical courses, etc.

Based on the above five aspects, this paper establishes an evaluation index system based on the expert survey method. Together, there are 5 primary indicators, 10 secondary indicators and 25 tertiary indicators.

\subsection{Empirical analysis.}

According to the method of fuzzy comprehensive evaluation, combined with the survey results, according to experts on the related areas of each evaluation index to make comparative evaluation, respectively build primary index (A1, A2, A3, A4, A5) and secondary index (B11, B12), (B21, B22) and (B31, B32), (B41, B42), (B51, b-52). Through the solution, the CR of the judgment matrix is less than 0.1 , and the weight of the primary and secondary indexes can be obtained through the consistency test.

By computing, we can see that the identification matrix is evaluated
$R 11=\left[\begin{array}{lllll}0 & 0 & 0.4 & 0.6 & 0 \\ 0.2 & 0.4 & 0.2 & 0.2 & 0\end{array}\right]$

The weight vector of $\mathrm{c} 111-\mathrm{c} 112$ is $\mathrm{W} 11=(0.6,0.4)$, The degree of membership of the evaluation level is $\mathrm{B} 11=(0.08,0.16,0.32,0.44,0)$, The same thing can be calculated 


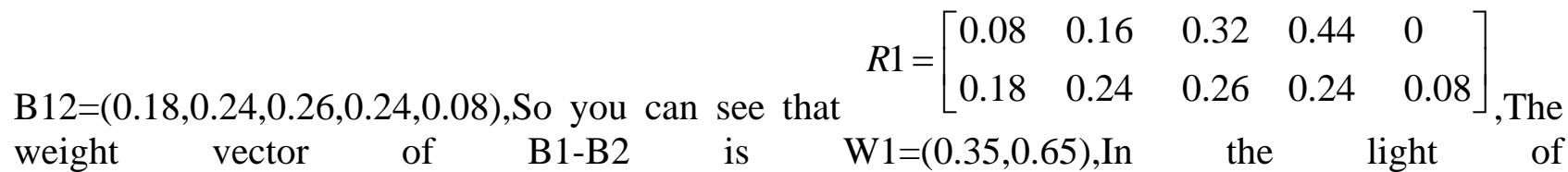
$\mathrm{B} 1=\mathrm{W} 1 \mathrm{R} 1$, therefore, $\mathrm{B} 1=(0.145,0.212,0.281,0.396,0.052)$ 。 And the same thing is true : $\mathrm{B} 2=\mathrm{W} 2 \mathrm{R} 2=(0.077,0.259,0.287,0.289,0.028), \mathrm{B} 3=\mathrm{W} 3 \mathrm{R} 3=(0,0.163,0.28,0.37,0.762), \mathrm{B} 4=\mathrm{W} 4 \mathrm{R} 4=(0.0$ $6,0.241,0.271,0.324,0.057), \mathrm{B} 5=\mathrm{W} 5 \mathrm{R} 5=(0.299,0.33,0.365,0.301,0.086)$ 。 According to the above calculation, the evaluation identification matrix of education system of innovation and entrepreneurship of the university is $\mathrm{R}=\left(B 1^{T}, B 2^{T}, B 3^{T}, B 4^{T}, B 5^{T}\right)$, Weight of all factors $\mathrm{W}=(0.19,0.28,0.17,0.11,0.25)$. Therefore, the comprehensive evaluation vector for the education system of innovation and entrepreneurship in this business school isB $=W R=(0.132,0.251,0.302,0.33,0.173)$. According to the evaluation criteria determined by the expert group, the comprehensive evaluation score of the school is 79.1. The quality level of the education system is medium. In terms of the specific situation of the school, it is relatively good in school support and students' quality, and it needs to continue to develop in government support and financial platform.

\section{Acknowledgement}

Project supported by the national business education and research in 2017 annual issue (SKJYKT-1714)

Supported by Reasearch team building of Xi'an Fanyi University (xfu17kytda02)

\section{References}

[1] Zhishuai Song, Jinhua zhao. Based on the platform of "challenge cup" college students' innovative ability training study [J]. Journal of continuing education research, 2010(10),

[2] Zhishuai Song, Research on innovation ability of postgraduate students under the national innovation system [J], Continue Education Research, 2012(10)

[3] jiahua Li , xudong $\mathrm{Lu}$. The innovation and entrepreneurship education tremor into the talent training system of universities [J]. China higher education, 2010(12)

[5] wei liu. Litter of school innovation entrepreneurship education personnel training system to build thinking [J]. Journal of education science, 2011 (5) 